\title{
Identified Genomic Data and Samples
}

National Cancer Institute

\section{Source}

National Cancer Institute. Identified Genomic Data and Samples. NCI Thesaurus. Code C68755.

Identified data and samples are labelled with personal identifiers such as name or identification numbers (e.g., social security or national insurance number). As the samples and associated data are directly traceable back to the subject, it is possible to undertake actions such as sample withdrawal or the return of individual results. The use of identified data and samples allows for clinical monitoring, subject follow-up and the addition of new data. Identified data and samples coding offers privacy protection similar to general healthcare confidentiality in everyday medical practice. Identified data and sample coding are generally not considered appropriate for purposes of clinical trials in drug development. (ICH) 